\title{
Inappropriate shock in Brugada syndrome: incidence and predictors in patients with a subcutaneous implantable cardiac defibrillator
}

\author{
Gavino Casu ${ }^{1}$, Etelvino Silva ${ }^{2}$, Felipe Bisbal $^{3}$, Graziana Viola $^{1}$, Pierluigi Merella ${ }^{1}$, \\ Giovanni Lorenzoni ${ }^{1}$, Giovanni Motta ${ }^{1}$, Stefano Bandino ${ }^{1}$, and Paola Berne ${ }^{1}$ \\ ${ }^{1}$ Ospedale San Francesco \\ ${ }^{2}$ Hospital CLinic i Provincial de Barcelona \\ ${ }^{3}$ Hospital Clinic
}

January 18, 2021

\begin{abstract}
Abstract Background: Subcutaneous implantable cardioverter defibrillators (S-ICDs) avoid complications secondary to transvenous leads, but inappropriate shocks (ISs) are frequent. Furthermore, IS data from patients with Brugada syndrome (BrS) with an S-ICD are scarce. Objective: We aimed to establish the incidence, mechanisms, and predictors of S-ICD in this population. Methods: We analyzed the clinical and electrocardiographic characteristics, automated screening test data, device programming, and IS occurrence in adult patients with BrS with an S-ICD. Results: Thirty-nine patients were enrolled (69\% male, mean age at diagnosis $46 \pm 13$ years, mean age at implantation $48 \pm 13$ years). During a mean follow-up of $26 \pm 21$ months, $18 \%$ patients experienced IS. Patients with IS were younger at the time of diagnosis ( $36 \pm 8$ versus $48 \pm 13$ years, $\mathrm{p}=0.018)$ and S-ICD implantation ( $38 \pm 9$ versus $50 \pm 23$ years, $\mathrm{p}=0.019)$ and presented with spontaneous type 1 Brugada ECG pattern more frequently at diagnosis or during follow-up ( $71 \%$ versus $25 \%, \mathrm{p}=0.018)$. During automated screening tests, patients with IS showed lower QRS voltage in the primary vector in the supine position $(0.58 \pm 0.26$ versus $1.10 \pm 0.35 \mathrm{mV}, \mathrm{p}=0.011)$ and lower defibrillator automated screening score (DASS) in the primary vector in the supine ( $123 \pm 165$ versus $554 \pm 390 \mathrm{mV}$, p=0.005) and standing ( $162 \pm 179$ versus $486 \pm 388 \mathrm{mV}, \mathrm{p}=0.038)$ positions. Age at diagnosis was the only independent predictor of IS (hazard ratio $=0.873,95 \%$ confidence interval: $0.767-0.992, \mathrm{p}=0.037$ ). Conclusion: IS was a frequent complication in patients with BrS with an S-ICD. Younger age was independently associated with IS. A more thorough screening process might help prevent IS in this population.
\end{abstract}

\section{Hosted file}

Manuscript Inappropriate shock S-ICD BrS_Casu et al_JCE.pdf available at https://authorea. com/users/390037/articles/504480-inappropriate-shock-in-brugada-syndrome-incidence-andpredictors-in-patients-with-a-subcutaneous-implantable-cardiac-defibrillator 